\title{
Non-coding enhancer RNA regulates NPAS4 in the mPFC to control chronic stress-induced anhedonia-like behavior
}

Brandon W Hughes ${ }^{1}$, Benjamin M Siemsen ${ }^{1}$, Stefano Berto ${ }^{1}$, Jaswinder Kumar ${ }^{2,3}$,

Rebecca G Cornbrooks ${ }^{1}$, Rose Marie Akiki ${ }^{1}$, Jordan S Carter ${ }^{1}$, Emma C Brase ${ }^{1}$, Nobuya Koike $^{4}$, Michael D Scofield ${ }^{1}$, Christopher W Cowan ${ }^{1,2,5^{*}}$, Makoto Taniguchi ${ }^{1,2,5}$ *

1. Departments of Neuroscience and Psychiatry \& Behavioral Sciences, Medical University of South Carolina, Charleston, SC 29425, USA

2. Department of Psychiatry, Harvard Medical School, McLean Hospital, Belmont, MA 02478, USA

3. Neuroscience Graduate Program, University of Texas Southwestern Medical Center, Dallas, TX 75390, USA

4. Department of Physiology and Systems Bioscience, Kyoto Prefectural University of Medicine, Kyoto 602-8566, Japan

5. Lead Contact

*Correspondence: Cowanc@musc.edu and Taniguch@musc.edu

Phone: 843-792-2935 (Cowan) and 843-792-9772 (Taniguchi)

\section{Running title: NPAS4 and eRNA control chronic stress-induced anhedonia}

key words: Anhedonia, hypofrontality, chronic social defeat stress, mPFC, NPAS4, Incenhancer RNA 


\section{Abstract}

Background: Chronic stress can produce reward system deficits (i.e. anhedonia) and other common symptoms associated with depressive disorders, as well as neural circuit hypofunction in the medial prefrontal cortex (mPFC). However, the molecular mechanisms by which chronic stress promotes depressive-like behavior and hypofrontality remain poorly understood.

Methods: C57BL/6 adult male mice were subjected to chronic social defeat stress (CSDS). Neuronal PAS domain-containing protein 4 (NPAS4) or the Npas4 Inc-eRNA were reduced using a viral-mediated shRNA approach. CSDS-induced behaviors, including social avoidance, sucrose preference, natural reward motivation, and anxietylike behavior, were then measured. CSDS-induced changes in mPFC dendritic spine density were assessed using confocal imaging, and the mPFC NPAS4-regulated transcriptome was assessed using RNA-seq analysis.

Results: Social defeat stress induced transient expression of NPAS4 in the mPFC. Viralmediated knockdown of mPFC NPAS4 blocked CSDS-induced reduction in sucrose preference and changes in natural reward motivation, but without influencing social avoidance. NPAS4 was also required for CSDS-induced reduction of pyramidal neuron dendritic spine density in mPFC. RNA-seq analysis from mPFC tissues revealed that NPAS4 influences expression of numerous genes linked to glutamatergic synapses and ribosomal function, and to genes dysregulated in multiple neuropsychiatric disorders, including depression. Finally, we found that stress-induced expression of NPAS4 in mPFC requires a novel, activity-regulated Inc-eRNA, and that this Npas4 Inc-eRNA in mPFC was required for CSDS-induced anhedonia-like behavior. 
Conclusion: Together our findings reveal a novel, stress-regulated and Inc-eRNAdependent transcriptional mechanism in the mPFC that promotes dendritic spine loss and development of anhedonia-like behaviors.

\section{Introduction}

Stress-related mental disorders continue to be a leading cause of disability and financial burden on society (1). The associated symptom domains of stress-related disorders are diverse and present with a high degree of comorbidity, thus treatment strategies for these disorders represent a major healthcare challenge. The rodent chronic social defeat stress (CSDS) paradigm produces multiple behavioral and neural phenotypes reminiscent of stress-related and depressive disorders in humans (2-15), including anhedonia-like behaviors and social avoidance. CSDS produces social avoidance in a subset of mice (often termed the "susceptible" population); whereas the "resilient" subpopulation displays normal social behavior after $\operatorname{CSDS}(8,12,13)$. Anhedonia, a core symptom of major depressive disorder (MDD), is associated with deficits in hedonic capacity, reward evaluation, decision-making, and motivation to obtain rewards, as well as risk for suicide and treatment resistance $(16,17)$. However, the neural mechanisms by which chronic stress produces anhedonia remain unclear. Multiple preclinical and clinical studies have revealed reduced function of the medial prefrontal cortex (mPFC), which is caused, at least in part, by stress-induced loss of structural and functional synaptic connections and neural circuits in this region $(3,18-21)$. Furthermore, stress-induced hypofrontality is thought to underlie symptoms of $\operatorname{MDD}(17,22-25)$ and contribute to the neuropathology 
of treatment-resistant depression (26), including the potential for anhedonia susceptibility $(27,28)$.

Unbiased RNA sequencing approaches have revealed robust and widespread expression of long non-coding RNAs (IncRNAs) throughout the brain $(26,28-31)$. IncRNAs, including those produced from genomic enhancers (referred to as enhancer RNAs or eRNAs), play important roles in the regulation of gene expression through various mechanisms, such as chromosomal looping, modulating protein:protein interactions, and regulation of histone modifications (32-36). However, the importance of eRNAs in healthy brain function is largely unexplored.

In this study, we investigated the role of Neuronal PAS domain Protein 4 (NPAS4), and its eRNA transcribed from the Npas4 enhancer region ( $\sim 3 \mathrm{~kb}$ upstream of the TSS), in chronic stress-induced brain and behavior dysfunction. NPAS4 is an immediate early gene (IEG) transcription factor that modulates synaptic connections on excitatory $(E)$ and inhibitory (I) neurons in response to synaptic activity - a proposed homeostatic mechanism to modulate $\mathrm{E} / \mathrm{I}$ balance in strongly activated neural circuits (37-42). In the brain, NPAS4 is required in the hippocampus and amygdala for contextual fear learning $(43,44)$, in the visual cortex for social recognition $(45)$, and in the nucleus accumbens (NAc) for cocaine reward-context learning and memory (46). Here, we discovered that acute social stress or CSDS induces NPAS4 expression in the mPFC and that NPAS4 in the $\mathrm{mPFC}$ is required for both CSDS-induced anhedonia and reduction of dendritic spine density. Similarly, we found that the Npas4 eRNA was required for CSDS-induced mPFC Npas4 mRNA expression and anhedonia-like behaviors, revealing an essential role for a non-coding eRNA in chronic stress-induced behavioral dysfunction. 


\section{Methods and Materials}

\section{Recombinant plasmids and shRNA expression viral vectors}

For knockdown of endogenous Npas4 mRNA and eRNA expression in medial prefrontal cortex (mPFC), validated anti-Npas4 shRNA or scramble (SC) shRNA control (Lin et al 2008 and Taniguchi 2017) and anti-Npas4 eRNA shRNA oligonucleotides were cloned into the pAAV-shRNA vector as previously described (46). See the Supplemental Table S3 for sequence of shRNAs. The adeno-associated virus serotype 2 (AAV2) vector consists of a CMV promoter driving eGFP with a SV40 polyadenylation signal, followed downstream by a U6 polymerase III promoter and Npas4 mRNA shRNA, Npas4 eRNA shRNA, or SC shRNA oligonucleotides, then a polymerase III termination signal - all flanked by AAV2 inverted terminal repeats. AAV2-Npas4 mRNA shRNA, eRNA shRNA, and SC shRNA were processed for packaging and purification (UNC Vector Core, NC, and USC Vector Core, SC).

\section{Viral-mediated gene transfer}

Stereotaxic surgery was performed under general anesthesia with a ketamine/xylazine cocktail (120 mg/kg: $16 \mathrm{mg} / \mathrm{kg}$ ) or isoflurane (induction 4\% v/v, maintenance 1\%-2\% v/v). Coordinates to target the mPFC (ventral portion of cingulate, prelimbic, and infralimbic cortices) were $+1.85-1.95 \mathrm{~mm}$ anterior, $+0.75 \mathrm{~mm}$ lateral, and 2.65 to $2.25 \mathrm{~mm}$ ventral from bregma (relative to skull) at a 15 degrees angle in all mice (3). AAV2-scramble (SC) shRNA $\left(2.9^{*} 10^{\wedge 9}\right.$ and $\left.1.1{ }^{*} 10^{12} \mathrm{GC} / \mathrm{mL}\right)$, AAV2-Npas4 shRNA $\left(4.3^{*} 10^{\wedge 9}\right.$ and $3.1^{*} 10^{12}$ $\mathrm{GC} / \mathrm{mL})$, and AAV-eRNA shRNA $\left(2.13^{*} 10^{13}\right.$ and $\left.1.49{ }^{*} 10^{14} \mathrm{GC} / \mathrm{mL}\right)$ were delivered using 
Hamilton syringes or nano injectors with pulled glass capillaries at a rate of $0.1 \mu \mathrm{L} / \mathrm{min}$ for $0.4 \mu \mathrm{L}$ at the dorsovental sites, followed by raising the needle and an additional $0.4 \mu \mathrm{L}$ delivery of virus. After waiting for an additional 5-10 min, needles were completely retracted. Viral placements were confirmed through immunohistochemistry for bicistronic expression of eGFP from the AAV2 viral vectors by experimenters blinded to the experimental conditions. Animals with off-target virus infection or no infection in either hemisphere were excluded from the analysis of behavioral phenotypes.

\section{Chronic social defeat stress}

Chronic social defeat stress (CSDS) was performed as previously described $(6,8)$. CD1 retired male breeders (Charles River Laboratory, CA) were single-housed for 3-5 days before CSDS procedures to establish their territorial cage, then pre-screened for aggressive behavior. Experimental C57BL/6J male mice were introduced to the aggressor's territorial cage, physically contacted and attacked by the aggressor for 5-10 min, and then separated by a clear plastic board with multiple small holes for 24 hours. Experimental mice were introduced to a new CD1 aggressor each day. The no stress control mice were housed with another non-stressed C57BL/6J male mouse, separated by the same plastic board, and the cage partner was changed every day for 10 days of the CSDS experiment.

\section{Results}

\section{Social defeat stress induces NPAS4 expression in the mPFC}


We first examined the expression of Npas 4 mRNA in two key corticolimbic regions associated with stress and reward, the mPFC and the nucleus accumbens (NAc), following 11 days of CSDS. We compared CSDS responses to a single social defeat stress experience (acute stress; Figure 1A). In the mPFC, we observed a very rapid and transient induction of Npas4 mRNA in the mPFC (Figure 1B) and NAc (Supplemental Figure S1). We observed a similar response with cFos mRNA, albeit a slower induction and longer duration (Figure 1C). Interestingly, CSDS-induced expression of Npas4 and cFos was observed, but it was reduced compared to the acute stress response (Figure 1B-C), possibly as a consequence of CSDS-induced mPFC hypofunction. In contrast, and in support of this hypothesis, the CSDS-induced attenuation of Npas4 induction was not observed in the NAc (Supplemental Figure S1). Similar to the Npas4 mRNA induction, we observed a significant increase in cells expressing NPAS4 protein at $1 \mathrm{hr}$ following CSDS or acute stress exposure in multiple mPFC regions, including the anterior cingulate and prelimbic cortex subregions (Figure 1D). Interestingly, the vast majority ( 70\%) of NPAS4+ neurons in the mPFC were CaMKIl $\alpha$-expressing pyramidal neurons (Figure 1E). Similar to the mRNA, the relative NPAS4 protein expression per cell was highest following acute stress (Supplemental Figure S1B), suggesting that acute stress and CSDS activate a similar number of NPAS4+ mPFC neurons, but that the relative induction of NPAS4 within each cell becomes weaker following repeated psychosocial stress (Supplemental Figure S1B).

\section{NPAS4 in the MPFC is required for CSDS-induced anhedonia-like behavior, but not social avoidance.}


To examine the function of NPAS4 in CSDS-induced behaviors (Figure 2A), we employed a neurotropic AAV-mediated RNA-interference approach (AAV2-Npas4 shRNA) to reduce endogenous Npas4 in the mPFC (Figure 2B). Adult male mice (C57BL/6J) received a bilateral injection of AAV2-Npas4 shRNA (Npas4 shRNA ${ }^{\mathrm{PFC}}$ ) or AAV2scrambled shRNA control (SC shRNA ${ }^{\mathrm{PFC}}$ ). Subsequently, the mice were subjected to 10 days of CSDS or no stress and were then tested for sociability, natural reward preference and motivation, and anxiety-like behavior (Figure 2A). The CSDS-treated SC shRNA ${ }^{\mathrm{PFC}}$ and Npas4 shRNA ${ }^{\mathrm{PFC}}$ mice showed a significant reduction in the time spent interacting with a novel social target (Figure 2C-D), suggesting that mPFC NPAS4 is not required for CSDS-induced social avoidance. In addition, there was no significant difference between Npas4 shRNA ${ }^{\mathrm{PFC}}$ vs. SC shRNA ${ }^{\mathrm{PFC}}$ in the relative distribution of CSDS-treated mice that were "resilient" (i.e. $>1.0$ social interaction ratio) vs. "susceptible" (i.e. $<1.0$ social interaction ratio) (Figure 2D). However, unlike the CSDS-treated SC shRNA ${ }^{\mathrm{PFC}}$ mice, CSDS-treated Npas4 shRNA ${ }^{\mathrm{PFC}}$ mice did not develop anhedonia-like behavior measured in the sucrose preference test (Figure 2E), revealing an important role for NPAS4 in stress-induced anhedonia-like behavior. Interestingly, CSDS increased anxiety-like behavior, as measured in the elevated plus maze, in both SC shRNAPFC and Npas4 shRNA ${ }^{\mathrm{PFC}}$ mice (Figure $2 \mathrm{~F}$ ), indicating that mPFC NPAS4 function is required for some, but not all, of the behavioral sequelae of CSDS. Moreover, the presence of CSDSinduced social avoidance and anxiety-related behavior in Npas4 shRNA ${ }^{\mathrm{PFC}}$ mice argues against the possibility that they are simply less sensitive to stress and/or have deficits in threat-related learning and memory. 
Individuals who suffer from pathological stress often exhibit deficits in motivated, effort-based decision-making (47-51). However, the molecular mechanisms underlying chronic stress-induced deficits on the motivation behavior has remained unclear. To examine the role of NPAS4 in CSDS-induced changes in reward motivation, Npas4 shRNA ${ }^{P F C}$ or SC shRNAPFC mice were allowed to self-administer sucrose (sucrose SA) under operant conditions. After stable sucrose SA was established, we examined motivation to work for a sucrose reward using the progressive ratio (PR) test (Figure 2A). Reduction of mPFC Npas4 did not alter the normal acquisition of sucrose SA, including normal operant discrimination learning (nosepokes in the active vs. inactive port) (Supplemental Figure S2A and S2B), but we did detect significant differences in the PR breakpoint - the maximum number of nosepokes an animal was willing to perform to receive a reward. In SC shRNAPFC mice, CSDS produced an increase in the PR breakpoint in "resilient", but not "susceptible," mice (Figure 2G) suggesting that "resilience" was associated with increased reward motivation after chronic stress. In stark contrast, mice lacking Npas4 in the mPFC showed the opposite effect on PR breakpoint (Figure 2G), suggesting that mPFC NPAS4 regulates CSDS-induced changes in reward motivation. Together, these data suggest that NPAS4 in the mPFC controls anhedonialike behavior in chronic stress-susceptible animals.

\section{NPAS4 regulates CSDS-induced reductions in mPFC dendritic spine density}

CSDS-induced reduction of dendritic spine density on mPFC pyramidal neurons is a putative pathophysiological underpinning of depression-associated behavior (52-58). As such, following CSDS we quantified dendritic spine density on SC or Npas4 shRNA- 
expressing mPFC deep-layer pyramidal neurons. Not surprisingly, we observed a CSDSinduced reduction in dendritic spine density in SC shRNA control mice (Fig. 3A-B, left). Unlike SC shRNA control mice, CSDS failed to reduce mPFC dendritic spine density in Npas4 shRNA-expressing neurons (Figure 3A-B, right), suggesting that NPAS4, directly or indirectly, is required for this chronic stress-induced structural synaptic change. We did not observe any changes in mPFC dendritic spine density in Npas4 shRNA-expressing neurons under the "no stress" control condition (Figure 3A-B), indicating that in the absence of CSDS, NPAS4 is not required to maintain steady-state dendritic spine density in adult mPFC pyramidal neurons (Figure 3A-B). Of note, neither Npas4 shRNA nor CSDS produced any detectible changes in mean dendritic spine head diameter (Supplemental Figure S3A)

\section{NPAS4 controls the expression of genes linked to the ribosome and to glutamatergic synapses}

To analyze the influence of NPAS4 on the mPFC transcriptome, we performed RNA-seq analyses with mPFC tissue isolated from SC shRNA ${ }^{\mathrm{PFC}}$ and Npas4 shRNA ${ }^{\mathrm{PFC}}$ mice. Of the $~ 700$ differentially expressed genes (DEGs) with Npas4 mRNA knockdown in mPFC, 634 were down-regulated and 50 were up-regulated (Supplemental Table S2).. Downregulated genes included Spata3, Defb1, Cidea, Psmb10, and Rspo3, and upregulated genes included Dapk2, Apcdd1, Schip1, Igfn1, and Arc (Figure 3B3C). A subset of these DEGs was independently validated by qRT-PCR using independent mPFC samples isolated from SC shRNA ${ }^{\mathrm{PFC}}$ and Npas4 shRNA ${ }^{\mathrm{PFC}}$ mice, including Nfix (Nuclear Factor I X), Sst (Somatostatin), Nrp1 (Neuropilin 1), Dhcr7 (7- 
Dehydrocholesterole Reductase), and Ache (Acetylcholinesterase) (Supplemental Figure S3B). Pathway analyses of Npas4 shRNA downregulated DEGs revealed significant enrichment of genes linked to ribosome function and upregulated DEGs showed significant enrichment of glutamatergic synapse-related genes (Figure 3D). We detected 92 total ribosome-related genes in the mPFC, and of these, 64 were significantly downregulated (FDR < 0.05) and one was upregulated by Npas4 shRNA (Figure 3F). Additionally, Npas4 shRNA DEGs were significantly enriched in two PsychENCODE modules (Figure 3E and Supplemental Table S2) $(59,60)$. Npas4 shRNA-downregulated DEGs showed significant enrichment within gene module M15, an excitatory neuron module of genes that are associated with ribosome function and upregulated in Autism Spectrum Disorder (ASD) and Bipolar Disorder (BD). Interestingly, RNA-seq from human postmortem brains (BA8/9) of male MDD patients indicated significant enrichment of DEGs in ribosome-related pathways, identifying 69 upregulated and 8 downregulated genes in MDD patients (Figure 3F) (61). Moreover, the majority (64.1\%) of the Npas4 shRNA DEGs from our analysis overlapped with upregulated genes in human MDD patients (Figure 3F). Finally, Npas4 shRNA upregulated DEGs showed significant PsychENCODE enrichment in gene module M1, an excitatory neuron module of genes that are associated with glutamate-driven excitability of neurons and downregulated in ASD (59). Together, these data suggest that NPAS4 in the mPFC regulates numerous genes related to glutamatergic synapses and ribosomal function that might contribute to stress-related anhedonia. Moreover, the enrichment of NPAS4-regulated genes in multiple neuropsychiatric disorders, including MDD (61), positions NPAS4 as an important factor in brain health and disease. 


\section{Npas4 Inc-eRNA regulates Npas4 mRNA expression and anhedonia-like behavior}

Next, we sought to examine the stress-dependent regulation of Npas4 mRNA in the mPFC. From total RNA-seq data from primary cultured neurons, we detected an eRNA mapping to an activity-regulated Npas 4 enhancer region located $\sim 3$ kilobase pairs upstream of the Npas4 gene (Figure 4A) (46). This Npas4 enhancer associates with multiple transcription factors, epigenetic enzymes, and histone modifications (Figure 4A), some of which play critical roles in regulating basal and activity-dependent Npas4 gene expression (Supplemental Figure S4A) (46). Moreover, membrane depolarization of cultured primary cortical neurons significantly increased both Npas4 mRNA and eRNA expression (Figure 4B and 4C, respectively).

To examine the functional role of the Npas 4 eRNA, we next designed and validated an AAV2-shRNA vector to reduce Npas4 eRNA levels in vitro and in vivo (Figure 4E-H). Interestingly, the Npas4 eRNA shRNA also significantly decreased Npas4 mRNA expression (Figure 4F), revealing that the Npas4 eRNA is critical for Npas4 mRNA expression. Consistent with this idea, Npas4 eRNA overexpression was sufficient to increase Npas4 mRNA (Figure 4D). Following acute SDS, Npas4 mRNA was significantly increased in mPFC tissues, but this was significantly reduced by the AAV2-eRNA shRNA (Figure 4H), suggesting an important support role for Npas4 eRNA in regulation of Npas4 mRNA expression. In contrast, mPFC AAV2-eRNA shRNA had no effect on the expression of cFos mRNA (Supplemental Figure S4C), suggesting that the function of Npas4 eRNA is specific for Npas4 mRNA expression and not an indirect effect on neuronal activity or general IEG expression mechanisms. Finally, we assessed whether 
mPFC Npas4 eRNA was required for CSDS-induced anhedonia-like behavior. Following bilateral infusion of AAV2-eRNA shRNA or AAV2-SC shRNA into the mPFC, mice were allowed to recover and then subjected to 10 days of CSDS and depressive-like behavior testing. Similar to knockdown of Npas4 mRNA in mPFC (Figure 2), the AAV-eRNA shRNA blocked CSDS-induced reduction of sucrose preference, without altering sucrose preference in the "no stress" control mice (Figure 4I). These data suggest that Npas4 eRNA is required in mPFC for CSDS-induced expression of Npas4 mRNA, producing anhedonia-like behaviors.

\section{Discussion}

Here we find that social defeat stress (acute or chronic) induces rapid and transient expression of NPAS4 in mPFC neurons and that NPAS4 in the mPFC is required for CSDS-induced anhedonia-like behavior, changes in effort-based reward seekingmotivated behavior in CSDS-susceptible animals, and CSDS-induced dendritic spine loss on mPFC pyramidal neurons. However, mPFC NPAS4 was not required for CSDSinduced social avoidance or anxiety-like behavior, suggesting that CSDS produces different depressive-like phenotypes through distinct molecular and/or circuit mechanisms. In addition, we discovered that Npas4 shRNA dysregulated $~ 700$ mPFC genes, including upregulation of genes linked to glutamatergic synapses, suggesting that, following CSDS, NPAS4 might directly or indirectly downregulate these synapse-related genes to enable structural dendritic spine reduction. We also detected strong enrichment of downregulated ribosomal genes, and many of these are also dysregulated in human MDD. Finally, we discovered a novel Inc-RNA, Npas4 eRNA, that is transcribed from an 
activity-sensitive Npas4 enhancer, is required for normal social defeat stress-induced Npas4 mRNA expression in the mPFC and subsequent CSDS-induced anhedonia-like behavior. Together, our findings reveal a novel and essential role for mPFC NPAS4 in the induction of anhedonia-related behavior and structural synaptic changes produced by CSDS.

NPAS4 is a neuronal-specific, synaptic activity-regulated and experiencedependent transcription factor that regulates excitatory/inhibitory synapse balance and synaptic transmission $(37,38,40,41,62)$, promoting cell type-specific gene programs and cellular responses. Synaptic activity-dependent induction of NPAS4 in pyramidal neurons reduces excitatory synaptic transmission onto these neurons (38) and decreases excitatory synaptic inputs (39), consistent with our finding that NPAS4 is required for CSDS-induced loss of mPFC pyramidal neuron dendritic spine density. While one report indicated that CSDS-induced reduction of dendritic spine density is associated with social avoidance phenotypes (63), we observed that mPFC NPAS4 reduction selectively blocked CSDS-induced spine loss and anhedonia, but not social avoidance and anxietylike behavior, suggesting that deep-layer mPFC pyramidal cell spine loss, per se, is not required for the expression of social and anxiety-related phenotypes in the CSDS model. Interestingly, chronic exposure to stress hormones, chronic mild unpredictable stress, and chronic restraint stress also induce anhedonia-like behavior and dendritic spine loss (20, 54, 57, 64-71), and PFC pyramidal cell dendritic spine density is also reduced in human postmortem brains of individuals diagnosed with anhedonia-associated neuropsychiatric disorders, such as SCZ, BD, and MDD (57, 64, 72-79). These data support the possible functional relationship between PFC spine density and anhedonia. 
NPAS4 in cultured neurons regulates a large, cell type-specific program of gene expression, including key targets like brain-derived neurotrophic factor (BDNF), to alter E/I synapse balance $(14,37-41,44)$. However, social defeat stress failed to induce Bdnf mRNA in mPFC and Npas4 knockdown did not alter basal mPFC Bdnf expression (Figure 3C and Supplemental Table S2), suggesting that Bdnf is not a key downstream target of mPFC Npas4 in the context of CSDS. Our RNA-seq analysis of mPFC tissues, with or without Npas4 shRNA, revealed an abundance of significant DEGs (Figure 3C). Of the upregulated DEGs, gene ontology (GO) pathway analysis revealed enrichment of genes linked to glutamatergic synaptic transmission and excitability, and PsychENCODE analysis identified a neuronal module of genes linked to glutamatergic excitability that are downregulated in Autism Spectrum Disorders (59), suggesting the possibility that CSDSinduced mPFC dendritic spine density loss is produced, in part, by one or more of these synapse-linked genes that are downregulated following stress-induced mPFC NPAS4 expression. Interestingly, $22 \%$ of these upregulated DEGs overlapped with NPAS4 target genes identified by ChIP-seq analysis from cultured pyramidal neurons (33), suggesting that some of the upregulated, synapse-related DEGs could be direct NPAS4 gene targets. In contrast to the upregulated genes, downregulated Npas4 shRNA DEGs showed strong enrichment for ribosomal function and a PsychENCODE module (M15) of excitatory neuron genes associated with ribosome function that is upregulated in ASD and BD. While the functional relevance of ribosome gene enrichment is unclear, the marked enrichment of ribosome-related DEGs is very striking. Microarray analysis of blood samples from stress-vulnerable vs. stress-resistant adults found that DEGs were most markedly enriched in ribosome-related pathways and were upregulated based on stress 
vulnerability (80). Additionally, RNA-seq analyses from orbitofrontal cortex of postmortem human brains with SCZ, BD, and MDD also identified DEGs enriched for the ribosomal pathway, most of which were upregulated in patient samples (81). Together, these data suggest that NPAS4 regulates expression of numerous mPFC genes, including those linked to ribosome function and glutamatergic synapses, as well as genes dysregulated in patients with anhedonia-associated neuropsychiatric disorders, and that NPAS4 might promote anhedonia and hypofrontality through one or more of these gene targets.

We previously observed that HDAC5 associates with the Npas4 activity-sensitive enhancer region to limit the Npas4 mRNA expression in the NAc (46). Here, we found that a novel Inc-eRNA transcribed from the Npas4 enhancer region in mPFC is required for normal Npas4 mRNA expression and CSDS-induced anhedonia-like behavior. Multiple studies have reported IncRNA sequence variations in patients with neuropsychiatric disorders such as $\operatorname{BD}(82), \operatorname{SCZ}(83,84)$, and ASD (85). Long noncoding eRNAs are reported to epigenetically regulate gene expression through multiple mechanisms, including recruitment of transcriptional activators, evicting repressors, promoting epigenetic modifications, and modulating 3D chromatin looping $(32,33,86-92)$. In the future, it will be important to determine the precise cellular mechanisms by which Npas4 eRNA regulates Npas4 mRNA expression.

Overall, our findings reveal a novel role for mPFC NPAS4 in CSDS-induced anhedonia and pyramidal neuron dendritic spine loss, but not social avoidance or anxietylike behavior. NPAS4 in the mPFC regulates hundreds of genes, including clusters of genes linked to glutamatergic synapse function and ribosomal function, both of which are well-positioned to alter neuronal function. We find that social defeat stress induces 
expression of mPFC NPAS4 through a process requiring a long non-coding eRNA that is produced from a nearby activity-regulated enhancer, and targeted knockdown of the Npas4 eRNA blocks CSDS-induced anhedonia-like behavior. Therapeutic strategies targeting Npas4 or its regulatory eRNA could be a useful approach for treating PFC hypofrontality and anhedonia-related symptoms in patients struggling with depression, bipolar disorder, and other stress-related neuropsychiatric disorders.

\section{Acknowledgments}

The authors thank Rachel Penrod, Laura Smith, Yuhong Guo, Ben Zirlin, and Sara Pilling for technical assistance, comments on the manuscript, and helpful discussions. B.W.H. was supported by an NIH predoctoral fellowship (F31 DA048557 and T32 DA07288).

B.M.S. was supported by an NIH postdoctoral fellowship (F32 DA050427). M.T. was supported by a NARSAD Young Investigator Award from the Brain \& Behavior Research Foundation (Grant \#22765). This work was supported by grants from the NIH (UL1 TR001450 to M.T., DA032708 and DA046373 to C.W.C)

\section{Disclosures}

The authors report no biomedical financial interests or potential conflicts of interest.

\section{References}

1. Rehm J, Shield KD (2019): Global Burden of Disease and the Impact of Mental and Addictive Disorders. Current psychiatry reports. 21:10. 
2. Berton O, McClung CA, Dileone RJ, Krishnan V, Renthal W, Russo SJ, et al. (2006): Essential role of BDNF in the mesolimbic dopamine pathway in social defeat stress. Science. 311:864-868.

3. Covington HE, 3rd, Lobo MK, Maze I, Vialou V, Hyman JM, Zaman S, et al. (2010): Antidepressant effect of optogenetic stimulation of the medial prefrontal cortex. J Neurosci. 30:16082-16090.

4. Covington HE, 3rd, Maze I, LaPlant QC, Vialou VF, Ohnishi YN, Berton O, et al. (2009): Antidepressant actions of histone deacetylase inhibitors. J Neurosci. 29:11451-11460.

5. Fuchikami M, Yamamoto S, Morinobu S, Okada S, Yamawaki Y, Yamawaki S (2016): The potential use of histone deacetylase inhibitors in the treatment of depression. Prog Neuropsychopharmacol Biol Psychiatry. 64:320-324.

6. Golden SA, Covington HE, 3rd, Berton O, Russo SJ (2011): A standardized protocol for repeated social defeat stress in mice. Nat Protoc. 6:1183-1191.

7. Golden SA, Covington HE, 3rd, Berton O, Russo SJ (2015): Corrigendum: a standardized protocol for repeated social defeat stress in mice. Nat Protoc. 10:643.

8. Krishnan V, Han MH, Graham DL, Berton O, Renthal W, Russo SJ, et al. (2007): Molecular adaptations underlying susceptibility and resistance to social defeat in brain reward regions. Cell. 131:391-404.

9. Qu Y, Yang C, Ren Q, Ma M, Dong C, Hashimoto K (2017): Regional differences in dendritic spine density confer resilience to chronic social defeat stress. Acta Neuropsychiatr.1-6.

10. Venzala E, Garcia-Garcia AL, Elizalde N, Tordera RM (2013): Social vs. environmental stress models of depression from a behavioural and neurochemical approach. Eur Neuropsychopharmacol. 23:697-708. 
11. Vialou V, Bagot RC, Cahill ME, Ferguson D, Robison AJ, Dietz DM, et al. (2014): Prefrontal cortical circuit for depression- and anxiety-related behaviors mediated by cholecystokinin: role of DeltaFosB. J Neurosci. 34:3878-3887.

12. Krishnan V, Nestler EJ (2008): The molecular neurobiology of depression. Nature. 455:894-902.

13. Krishnan V, Nestler EJ (2011): Animal models of depression: molecular perspectives. Curr Top Behav Neurosci. 7:121-147.

14. Ye L, Allen WE, Thompson KR, Tian Q, Hsueh B, Ramakrishnan C, et al. (2016): Wiring and Molecular Features of Prefrontal Ensembles Representing Distinct Experiences. Cell. 165:17761788.

15. Venzala E, García-García AL, Elizalde N, Delagrange P, Tordera RM (2012): Chronic social defeat stress model: behavioral features, antidepressant action, and interaction with biological risk factors. Psychopharmacology (Berl). 224:313-325.

16. Der-Avakian A, Markou A (2012): The neurobiology of anhedonia and other rewardrelated deficits. Trends Neurosci. 35:68-77.

17. Llorca P, Gourion D (2015): Management of Anhedonia and Depressive Symptoms in Depressed Outpatients: Benefit for Functioning. Eur Psychiatry. 30:364-364.

18. Covington HE, 3rd, Kikusui T, Goodhue J, Nikulina EM, Hammer RP, Jr., Miczek KA (2005): Brief social defeat stress: long lasting effects on cocaine taking during a binge and zif268 mRNA expression in the amygdala and prefrontal cortex. Neuropsychopharmacology. 30:310-321.

19. Holmes A, Wellman CL (2009): Stress-induced prefrontal reorganization and executive dysfunction in rodents. Neurosci Biobehav Rev. 33:773-783. 
20. Radley JJ, Arias CM, Sawchenko PE (2006): Regional differentiation of the medial prefrontal cortex in regulating adaptive responses to acute emotional stress. J Neurosci. 26:12967-12976.

21. Arnsten AF, Raskind MA, Taylor FB, Connor DF (2015): The Effects of Stress Exposure on Prefrontal Cortex: Translating Basic Research into Successful Treatments for Post-Traumatic Stress Disorder. Neurobiol Stress. 1:89-99.

22. Galynker, II, Cai J, Ongseng F, Finestone H, Dutta E, Serseni D (1998): Hypofrontality and negative symptoms in major depressive disorder. J Nucl Med. 39:608-612.

23. Matsuo K, Kato T, Fukuda M, Kato N (2000): Alteration of hemoglobin oxygenation in the frontal region in elderly depressed patients as measured by near-infrared spectroscopy. J Neuropsychiatry Clin Neurosci. 12:465-471.

24. Suto T, Fukuda M, Ito M, Uehara T, Mikuni M (2004): Multichannel near-infrared spectroscopy in depression and schizophrenia: cognitive brain activation study. Biol Psychiatry. 55:501-511.

25. Matsuo K, Kato N, Kato T (2002): Decreased cerebral haemodynamic response to cognitive and physiological tasks in mood disorders as shown by near-infrared spectroscopy. Psychol Med. 32:1029-1037.

26. Li CT, Su TP, Wang SJ, Tu PC, Hsieh JC (2015): Prefrontal glucose metabolism in medication-resistant major depression. Br J Psychiatry. 206:316-323.

27. Gong L, He C, Zhang H, Zhang H, Zhang Z, Xie C (2018): Disrupted reward and cognitive control networks contribute to anhedonia in depression. J Psychiatr Res. 103:61-68. 
28. Gong L, Yin Y, He C, Ye Q, Bai F, Yuan Y, et al. (2017): Disrupted reward circuits is associated with cognitive deficits and depression severity in major depressive disorder. J Psychiatr Res. 84:917.

29. Guennewig B, Cooper AA (2014): The central role of noncoding RNA in the brain. Int Rev Neurobiol. 116:153-194.

30. Yang S, Lim KH, Kim SH, Joo JY (2020): Molecular landscape of long noncoding RNAs in brain disorders. Mol Psychiatry.

31. Mercer TR, Dinger ME, Sunkin SM, Mehler MF, Mattick JS (2008): Specific expression of long noncoding RNAs in the mouse brain. Proc Natl Acad Sci U S A. 105:716-721.

32. Arnold PR, Wells AD, Li XC (2019): Diversity and Emerging Roles of Enhancer RNA in Regulation of Gene Expression and Cell Fate. Frontiers in cell and developmental biology. 7:377.

33. Kim TK, Hemberg M, Gray JM, Costa AM, Bear DM, Wu J, et al. (2010): Widespread transcription at neuronal activity-regulated enhancers. Nature. 465:182-187.

34. Lam MT, Li W, Rosenfeld MG, Glass CK (2014): Enhancer RNAs and regulated transcriptional programs. Trends Biochem Sci. 39:170-182.

35. Khorkova O, Hsiao J, Wahlestedt C (2015): Basic biology and therapeutic implications of IncRNA. Adv Drug Deliv Rev. 87:15-24.

36. Gray JM, Kim TK, West AE, Nord AS, Markenscoff-Papadimitriou E, Lomvardas S (2015): Genomic Views of Transcriptional Enhancers: Essential Determinants of Cellular Identity and Activity-Dependent Responses in the CNS. J Neurosci. 35:13819-13826.

37. Bloodgood BL, Sharma N, Browne HA, Trepman AZ, Greenberg ME (2013): The activitydependent transcription factor NPAS4 regulates domain-specific inhibition. Nature. 503:121-125. 
38. Lin Y, Bloodgood BL, Hauser JL, Lapan AD, Koon AC, Kim TK, et al. (2008): Activitydependent regulation of inhibitory synapse development by Npas4. Nature. 455:1198-1204.

39. Sim S, Antolin S, Lin CW, Lin Y, Lois C (2013): Increased cell-intrinsic excitability induces synaptic changes in new neurons in the adult dentate gyrus that require Npas4. J Neurosci. 33:7928-7940.

40. Spiegel I, Mardinly AR, Gabel HW, Bazinet JE, Couch CH, Tzeng CP, et al. (2014): Npas4 regulates excitatory-inhibitory balance within neural circuits through cell-type-specific gene programs. Cell. 157:1216-1229.

41. Sun X, Lin Y (2016): Npas4: Linking Neuronal Activity to Memory. Trends Neurosci. 39:264275.

42. Sharma N, Pollina EA, Nagy MA, Yap EL, DiBiase FA, Hrvatin S, et al. (2019): ARNT2 Tunes Activity-Dependent Gene Expression through NCoR2-Mediated Repression and NPAS4-Mediated Activation. Neuron. 102:390-406.e399.

43. Ploski JE, Monsey MS, Nguyen T, DiLeone RJ, Schafe GE (2011): The neuronal PAS domain protein 4 (Npas4) is required for new and reactivated fear memories. PLoS One. 6:e23760.

44. Ramamoorthi K, Fropf R, Belfort GM, Fitzmaurice HL, McKinney RM, Neve RL, et al. (2011): Npas4 regulates a transcriptional program in CA3 required for contextual memory formation. Science. 334:1669-1675.

45. Heslin K, Coutellier L (2018): Npas4 deficiency and prenatal stress interact to affect social recognition in mice. Genes, brain, and behavior. 17:e12448. 
46. Taniguchi M, Carreira MB, Cooper YA, Bobadilla AC, Heinsbroek JA, Koike N, et al. (2017): HDAC5 and Its Target Gene, Npas4, Function in the Nucleus Accumbens to Regulate CocaineConditioned Behaviors. Neuron. 96:130-144 e136.

47. Porcelli AJ, Delgado MR (2017): Stress and Decision Making: Effects on Valuation, Learning, and Risk-taking. Curr Opin Behav Sci. 14:33-39.

48. Henriques JB, Davidson RJ (2000): Decreased responsiveness to reward in depression. United Kingdom: Taylor \& Francis, pp 711-724.

49. Pechtel P, Dutra SJ, Goetz EL, Pizzagalli DA (2013): Blunted reward responsiveness in remitted depression. J Psychiatr Res. 47:1864-1869.

50. Chen C, Takahashi T, Nakagawa S, Inoue T, Kusumi I (2015): Reinforcement learning in depression: A review of computational research. Neurosci Biobehav Rev. 55:247-267.

51. American Psychiatric Association (2013): Diagnostic and Statistical Manual of Mental Disorders. 5th ed. Washington, DC.

52. Cerqueira JJ, Taipa R, Uylings HB, Almeida OF, Sousa N (2007): Specific configuration of dendritic degeneration in pyramidal neurons of the medial prefrontal cortex induced by differing corticosteroid regimens. Cereb Cortex. 17:1998-2006.

53. Colyn L, Venzala E, Marco S, Perez-Otaño I, Tordera RM (2019): Chronic social defeat stress induces sustained synaptic structural changes in the prefrontal cortex and amygdala. Behav Brain Res. 373:112079.

54. Liston C, Miller MM, Goldwater DS, Radley JJ, Rocher AB, Hof PR, et al. (2006): Stressinduced alterations in prefrontal cortical dendritic morphology predict selective impairments in perceptual attentional set-shifting. J Neurosci. 26:7870-7874. 
55. McKlveen JM, Myers B, Flak JN, Bundzikova J, Solomon MB, Seroogy KB, et al. (2013): Role of prefrontal cortex glucocorticoid receptors in stress and emotion. Biol Psychiatry. 74:672-679.

56. Ota KT, Duman RS (2013): Environmental and pharmacological modulations of cellular plasticity: role in the pathophysiology and treatment of depression. Neurobiol Dis. 57:28-37.

57. Qiao H, Li MX, Xu C, Chen HB, An SC, Ma XM (2016): Dendritic Spines in Depression: What We Learned from Animal Models. Neural Plast. 2016:8056370.

58. Shu Y, Xu T (2017): Chronic Social Defeat Stress Modulates Dendritic Spines Structural Plasticity in Adult Mouse Frontal Association Cortex. Neural Plast. 2017:6207873.

59. Gandal MJ, Zhang P, Hadjimichael E, Walker RL, Chen C, Liu S, et al. (2018): Transcriptomewide isoform-level dysregulation in ASD, schizophrenia, and bipolar disorder. Science. 362.

60. Wang D, Liu S, Warrell J, Won H, Shi X, Navarro FCP, et al. (2018): Comprehensive functional genomic resource and integrative model for the human brain. Science. 362.

61. Bagot RC, Cates HM, Purushothaman I, Lorsch ZS, Walker DM, Wang J, et al. (2016): Circuit-wide Transcriptional Profiling Reveals Brain Region-Specific Gene Networks Regulating Depression Susceptibility. Neuron. 90:969-983.

62. Hartzell AL, Martyniuk KM, Brigidi GS, Heinz DA, Djaja NA, Payne A, et al. (2018): NPAS4 recruits CCK basket cell synapses and enhances cannabinoid-sensitive inhibition in the mouse hippocampus. Elife. 7.

63. Qu Y, Yang C, Ren Q, Ma M, Dong C, Hashimoto K (2018): Regional differences in dendritic spine density confer resilience to chronic social defeat stress. Acta Neuropsychiatr. 30:117-122. 64. Christoffel DJ, Golden SA, Russo SJ (2011): Structural and synaptic plasticity in stressrelated disorders. Rev Neurosci. 22:535-549. 
65. Brown SM, Henning S, Wellman CL (2005): Mild, short-term stress alters dendritic morphology in rat medial prefrontal cortex. Cereb Cortex. 15:1714-1722.

66. Cook SC, Wellman CL (2004): Chronic stress alters dendritic morphology in rat medial prefrontal cortex. J Neurobiol. 60:236-248.

67. Radley JJ, Sisti HM, Hao J, Rocher AB, McCall T, Hof PR, et al. (2004): Chronic behavioral stress induces apical dendritic reorganization in pyramidal neurons of the medial prefrontal cortex. Neuroscience. 125:1-6.

68. Radley JJ, Rocher AB, Janssen WG, Hof PR, McEwen BS, Morrison JH (2005): Reversibility of apical dendritic retraction in the rat medial prefrontal cortex following repeated stress. Exp Neurol. 196:199-203.

69. Radley JJ, Rocher AB, Miller M, Janssen WG, Liston C, Hof PR, et al. (2006): Repeated stress induces dendritic spine loss in the rat medial prefrontal cortex. Cereb Cortex. 16:313-320.

70. Mayanagi T, Sobue K (2019): Social Stress-Induced Postsynaptic Hyporesponsiveness in Glutamatergic Synapses Is Mediated by PSD-Zip70-Rap2 Pathway and Relates to Anxiety-Like Behaviors. Front Cell Neurosci. 13:564.

71. Goldwater DS, Pavlides C, Hunter RG, Bloss EB, Hof PR, McEwen BS, et al. (2009): Structural and functional alterations to rat medial prefrontal cortex following chronic restraint stress and recovery. Neuroscience. 164:798-808.

72. Forrest MP, Parnell E, Penzes P (2018): Dendritic structural plasticity and neuropsychiatric disease. Nat Rev Neurosci. 19:215-234.

73. Moyer CE, Shelton MA, Sweet RA (2015): Dendritic spine alterations in schizophrenia. Neurosci Lett. 601:46-53. 
74. Glausier JR, Lewis DA (2013): Dendritic spine pathology in schizophrenia. Neuroscience. 251:90-107.

75. Konopaske GT, Lange N, Coyle JT, Benes FM (2014): Prefrontal cortical dendritic spine pathology in schizophrenia and bipolar disorder. JAMA Psychiatry. 71:1323-1331.

76. Lewis DA, González-Burgos G (2008): Neuroplasticity of neocortical circuits in schizophrenia. Neuropsychopharmacology. 33:141-165.

77. Holmes SE, Scheinost D, Finnema SJ, Naganawa M, Davis MT, DellaGioia N, et al. (2019): Lower synaptic density is associated with depression severity and network alterations. Nat Commun. 10:1529.

78. Duman CH, Duman RS (2015): Spine synapse remodeling in the pathophysiology and treatment of depression. Neurosci Lett. 601:20-29.

79. Moda-Sava RN, Murdock MH, Parekh PK, Fetcho RN, Huang BS, Huynh TN, et al. (2019): Sustained rescue of prefrontal circuit dysfunction by antidepressant-induced spine formation. Science. 364.

80. Hori H, Nakamura S, Yoshida F, Teraishi T, Sasayama D, Ota M, et al. (2018): Integrated profiling of phenotype and blood transcriptome for stress vulnerability and depression. J Psychiatr Res. 104:202-210.

81. Darby MM, Yolken RH, Sabunciyan S (2016): Consistently altered expression of gene sets in postmortem brains of individuals with major psychiatric disorders. Transl Psychiatry. 6:e890.

82. Song JHT, Lowe CB, Kingsley DM (2018): Characterization of a Human-Specific Tandem Repeat Associated with Bipolar Disorder and Schizophrenia. Am J Hum Genet. 103:421-430. 
83. Eckart N, Song Q, Yang R, Wang R, Zhu H, McCallion AS, et al. (2016): Functional Characterization of Schizophrenia-Associated Variation in CACNA1C. PLoS One. 11:e0157086.

84. Ripke S, O'Dushlaine C, Chambert K, Moran JL, Kähler AK, Akterin S, et al. (2013): Genomewide association analysis identifies 13 new risk loci for schizophrenia. Nat Genet. 45:1150-1159.

85. Inoue YU, Inoue T (2016): Brain enhancer activities at the gene-poor 5p14.1 autismassociated locus. Sci Rep. 6:31227.

86. Telese F, Ma Q, Perez PM, Notani D, Oh S, Li W, et al. (2015): LRP8-Reelin-Regulated Neuronal Enhancer Signature Underlying Learning and Memory Formation. Neuron. 86:696-710.

87. Joo JY, Schaukowitch K, Farbiak L, Kilaru G, Kim TK (2016): Stimulus-specific combinatorial functionality of neuronal c-fos enhancers. Nat Neurosci. 19:75-83.

88. Schaukowitch K, Joo JY, Liu X, Watts JK, Martinez C, Kim TK (2014): Enhancer RNA facilitates NELF release from immediate early genes. Mol Cell. 56:29-42.

89. Malik AN, Vierbuchen T, Hemberg M, Rubin AA, Ling E, Couch CH, et al. (2014): Genomewide identification and characterization of functional neuronal activity-dependent enhancers. Nat Neurosci. 17:1330-1339.

90. Arner E, Daub CO, Vitting-Seerup K, Andersson R, Lilje B, Drabløs F, et al. (2015): Transcribed enhancers lead waves of coordinated transcription in transitioning mammalian cells. Science. 347:1010-1014.

91. Tyssowski KM, DeStefino NR, Cho JH, Dunn CJ, Poston RG, Carty CE, et al. (2018): Different Neuronal Activity Patterns Induce Different Gene Expression Programs. Neuron. 98:530-546.e511. 92. Levine M, Cattoglio C, Tjian R (2014): Looping back to leap forward: transcription enters a new era. Cell. 157:13-25. 
bioRxiv preprint doi: https://doi.org/10.1101/2021.03.04.433930; this version posted March 4, 2021. The copyright holder for this preprint (which was not certified by peer review) is the author/funder, who has granted bioRxiv a license to display the preprint in perpetuity. It is made available under aCC-BY-NC-ND 4.0 International license. 


\section{Figure Legends}

Figure 1. Social defeat stress induces NPAS4 expression in the mPFC

(A) Schematic illustration of experimental timeline of gene expression analyses following acute social defeat stress and 10 days of chronic social defeat stress (CSDS).

(B) and (C) Quantification of Npas4 and cFos mRNA expression following acute and chronic social defeat stress at $15 \mathrm{~min}, 1 \mathrm{~h}$, and $24 \mathrm{hr}$ ( $\mathrm{n}=5-10 /$ condition).

(D) Data plot represents fold change in NPAS4-positive cell number in mPFC subregions in anterior cingulate cortex, prelimbic cortex, and infralimbic cortex ( $n=5-10 /$ condition) after acute stress and CSDS.

(E) Data plot shows the percentage of CaMKIla-positive cells in NPAS4-positive cells within the MPFC after acute stress and CSDS ( $n=3-5 /$ condition). Scale bar, $10 \mu \mathrm{m}$.

Data shown are mean \pm SEM; ${ }^{*} p<0.05,{ }^{* *} p<0.01,{ }^{* * *} p<0.001,{ }^{* * * *} p<0.0001$. Also see Table S1 for detailed statistical analyses.

Figure 2. NPAS4 in the MPFC is required for CSDS-induced anhedonia-like behavior

(A) Schematic illustration of experimental timeline of behavioral test battery consisting of CSDS followed by social interaction (SI; C-D), sucrose preference (SP; E), elevated plus maze (EPM; F), sucrose self-administration, and progressive ratio testing (Suc-SA and PR; G). 
(B) AAV2-Npas4 shRNA in the adult male mPFC decreases stress-induced NPAS4 protein expression. Left: representative image showing AAV2-shRNA expression viral vector-mediated eGFP expression in the adult mice mPFC. Right: quantification of NPAS4-positive cells/100 $\mu \mathrm{m}^{2}$ ( $\mathrm{n}=3 /$ condition).

(C) and (D) CSDS decreases the time spent in the social interaction zone (C) and the social interaction ratio (D) in the SC shRNA ${ }^{\mathrm{PFC}}$ and Npas4 shRNA ${ }^{\mathrm{PFC}}$ mice after CSDS ( $n=12-15 /$ condition).

(E) CSDS-induced reduction of sucrose preference is blocked by Npas4 shRNA in the mPFC. $(n=9-19)$.

(F) CSDS reduces time spent in open arms (sec) in SC shRNA ${ }^{\mathrm{PFC}}$ and Npas4 shRNA PFC mice $(n=7-10)$.

(G) Npas4 shRNA in the mPFC controls CSDS-mediated effort-based reward seekingmotivated behavior. $(n=3-10)$.

\section{Figure 3. NPAS4 regulates CSDS-induced reductions in mPFC dendritic spine density and expression of genes associated with ribosome and glutamatergic synapses}

(A) and (B) NPAS4 regulates CSDS-induced reduction of dendritic spine density in the mPFC. (A) Representative images showing AAV2-shRNA expression viral vectormediated eGFP expression. Scale bar, $3 \mu \mathrm{m}$. (B) Quantification of dendritic spine density of deep layer mPFC pyramidal neurons from SC shRNA ${ }^{\mathrm{PFC}}$ and Npas4 shRNA ${ }^{\mathrm{PFC}}$ mice after CSDS or in no stress controls. ( $n=34-55 \mathrm{branch} / 8$ animals/condition). Data shown 
are mean \pm SEM; ${ }^{*} p<0.05,{ }^{* *} p<0.01,{ }^{* *} p<0.001,{ }^{* * *} p<0.0001$. Also see Table $\mathrm{S} 1$ for detailed statistical analyses.

(C) List of top differentially expressed genes in mPFC of Npas4 shRNAPFC mice.

(D) Gene ontology analysis of down- and up-regulated DEGs in Npas4 shRNAPFC mice.

(E) Npas4 DEG enrichment in gene modules that are dysregulated in neuropsychiatric disorders; Modules M1 and M15.

(F) Overlap of DEGs in Npas4 shRNA ${ }^{\mathrm{PFC}}$ mice (left; blue) and DEGs in BA8/9 of human MDD patients (right; pink).

Figure 4. Npas4 Inc-eRNA regulates Npas4 mRNA and CSDS-induced anhedonialike behavior

(A) UCSC genome browser view of the Npas4 genomic locus with ChIP-seq and RNAseq data. Black rectangle indicates the Npas4 enhancer region. Green shading indicates the eRNA transcript.

(B) and (C) Depolarization induces Npas4 mRNA (B) and Inc-eRNA (C) expression in primary cortical cultured neurons $(n=3)$.

(D-F) Npas4 Inc-eRNA bidirectionally regulates the Npas4 mRNA expression in Neuro2A cells. The data charts represent relative level of Npas4 mRNA with Npas4 Inc-eRNA overexpression (D), and shRNA-mediated reduction of Npas4 eRNA (E) and mRNA (F). ( $\mathrm{G}$ and $\mathrm{H}$ ) AAV2-mediated Npas4 eRNA shRNA in the mPFC controls Npas4 eRNA (G) and mRNA $(H)$ after acute stress or in no stress control mice $(n=5-7)$.

(I) CSDS-induced reduction of sucrose preference is blocked by the AAV2-mediated eRNA shRNA expression in the mPFC. $(n=7-18)$. 
bioRxiv preprint doi: https://doi.org/10.1101/2021.03.04.433930; this version posted March 4, 2021. The copyright holder for this preprint (which was not certified by peer review) is the author/funder, who has granted bioRxiv a license to display the preprint in perpetuity. It is made available under aCC-BY-NC-ND 4.0 International license.

Data shown are mean \pm SEM; ${ }^{*} p<0.05,{ }^{* *} p<0.01,{ }^{* * *} p<0.001,{ }^{* * *} p<0.0001$. Also see Table S1 for detailed statistical analyses. 
A

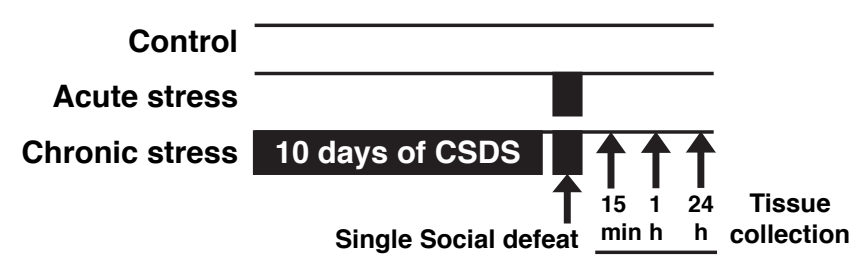

B

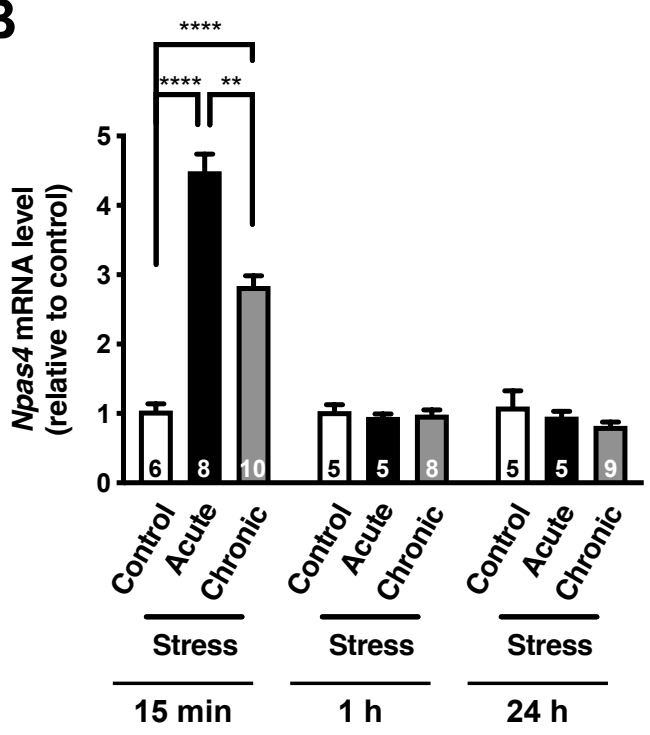

D

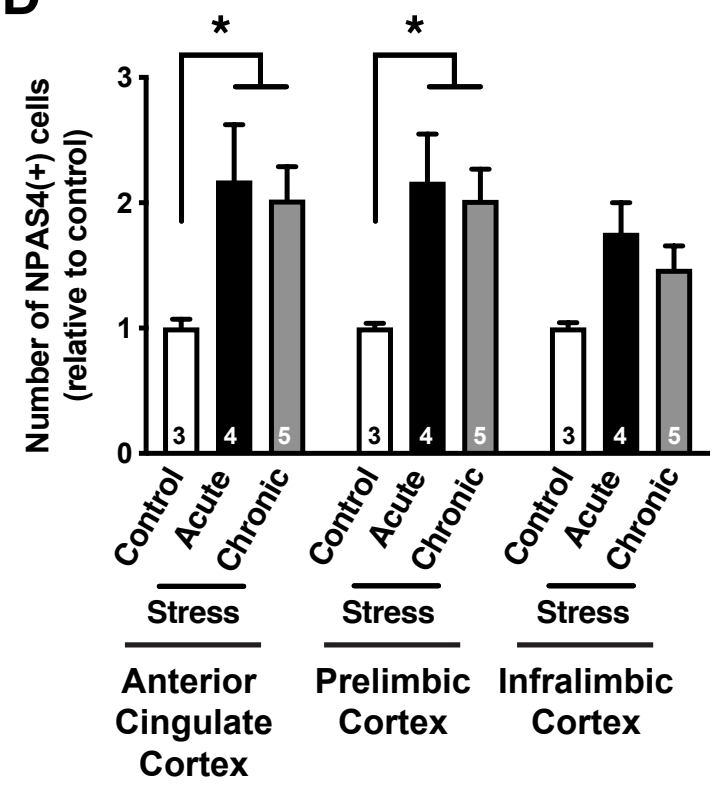

C

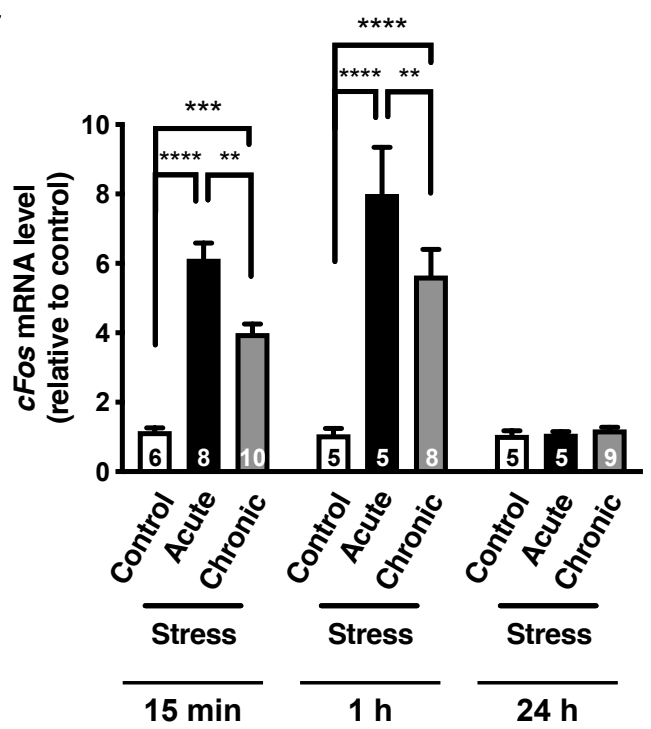

$\mathbf{E}$
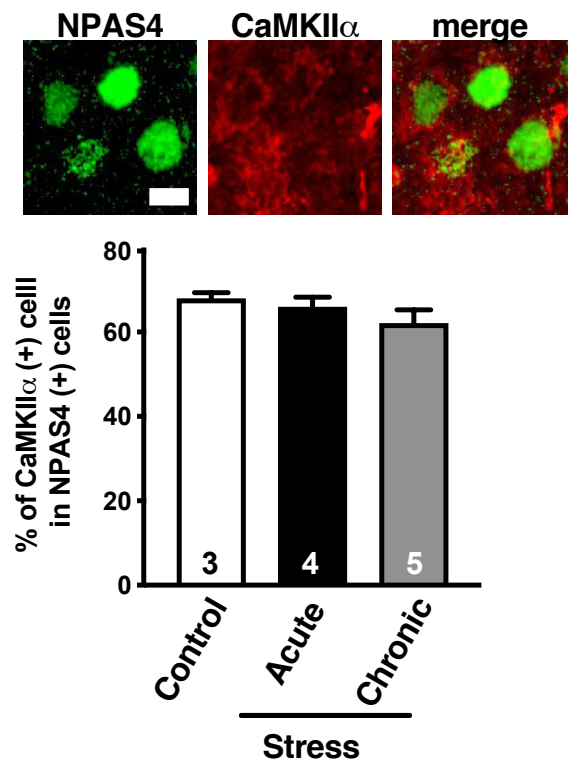
bioRxiv preprint doi: https://doi.org/10.1101/2021.03.04.433930; this version posted March 4, 2021. The copyright holder for this preprint (which was nt certified byBperew) is the author/funder, who has granted bioRxiv a license to display the preprint in perpetuity. It is made available under aCC-BY-NC-ND 4.0 International license.

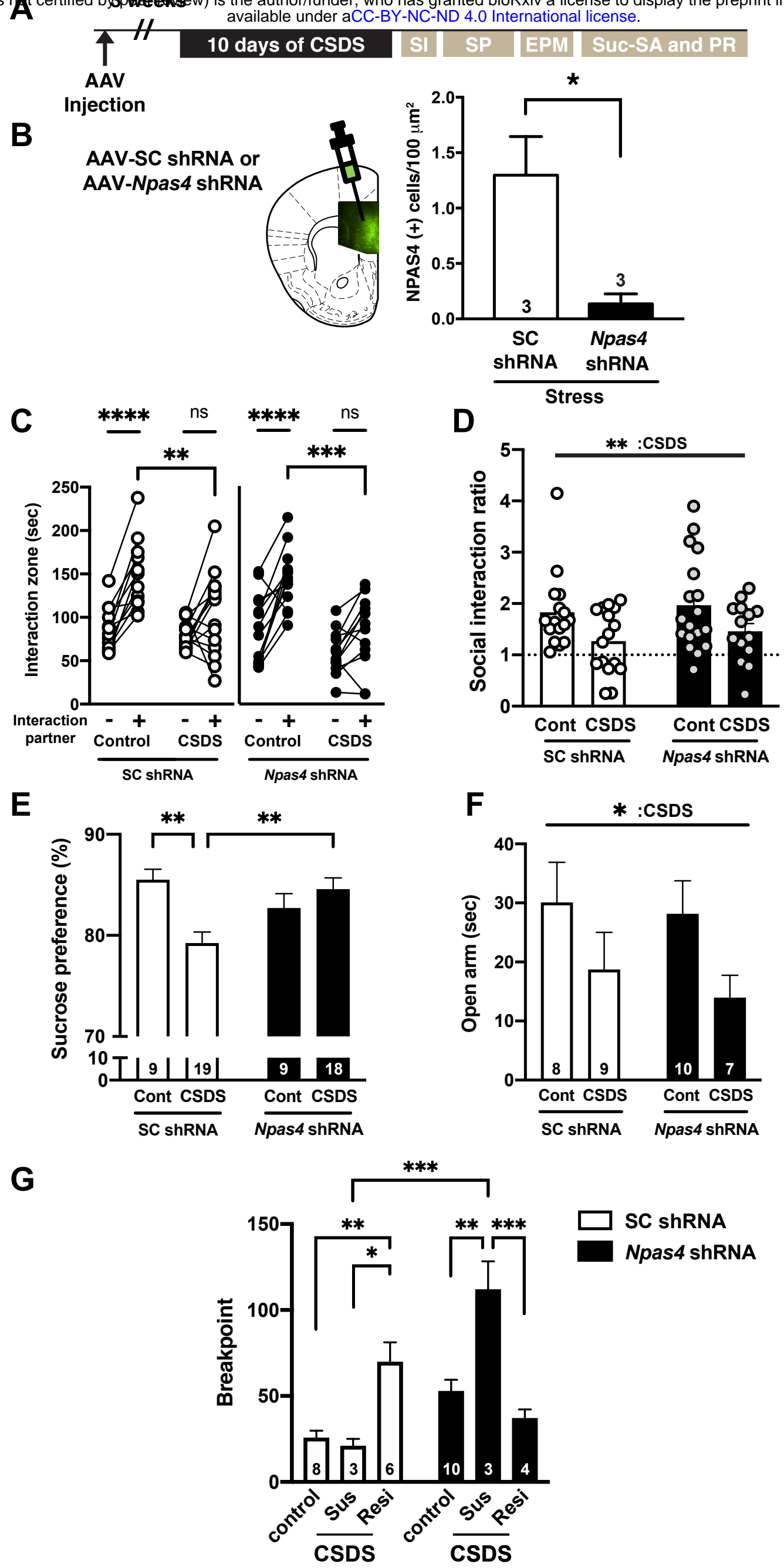


bioRxiv preprint doi: https://doi.org/10.1101/2021.03.04.433930; this version posted March 4, 2021. The copyright holder for this preprint (which was not certified by peer review) is the author/funder, who has grantedbioRxiv a license to display the prepristinfarpetuity. It is made
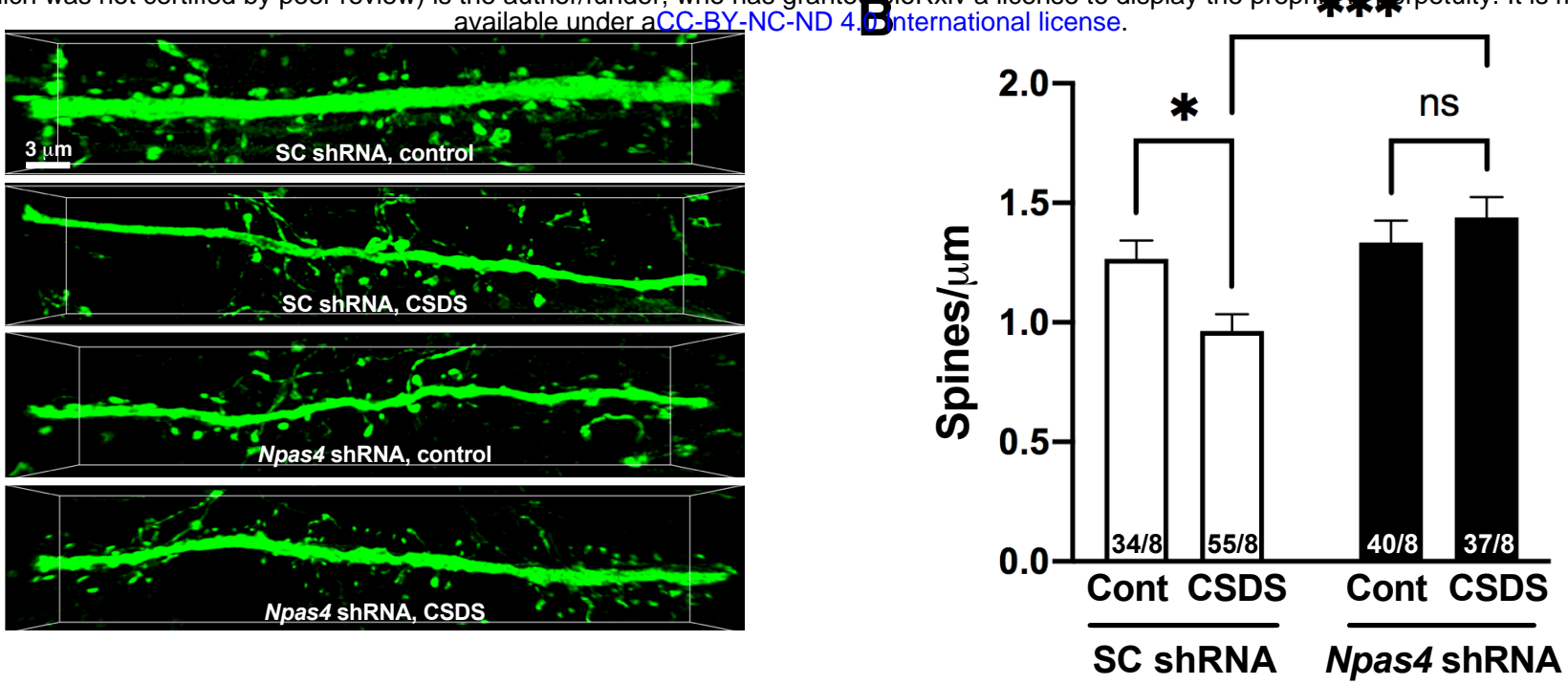

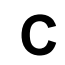

\begin{tabular}{|c|c|c|c|c|}
\hline & & \multicolumn{3}{|c|}{ NPAS4-mediated genes } \\
\hline & & Gene & FDR & $\log _{2}(F C)$ \\
\hline \multirow{5}{*}{ 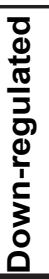 } & 1 & Spata3 & 0.0009 & -0.85 \\
\hline & 2 & Defb1 & 0.0005 & -0.72 \\
\hline & 3 & Cidea & 0.0009 & -0.65 \\
\hline & 4 & Psmb10 & 0.038 & -0.60 \\
\hline & 5 & Rspo3 & 0.035 & -0.58 \\
\hline \multirow{5}{*}{ 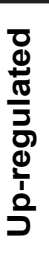 } & 5 & Dapk2 & 0.00002 & 0.70 \\
\hline & 4 & Apcdd1 & 0.035 & 0.73 \\
\hline & 3 & Schip1 & 0.029 & 0.74 \\
\hline & 2 & Igfn1 & 0.009 & 0.84 \\
\hline & 1 & Arc & 0.021 & 0.87 \\
\hline
\end{tabular}

E

PsychENCODE Gene Modules

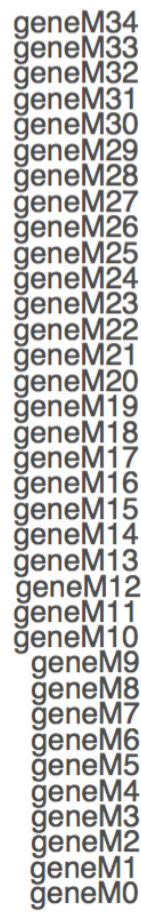

OR
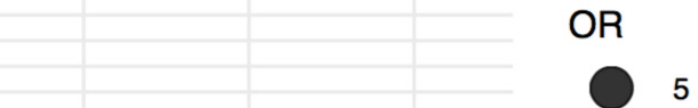

10

15
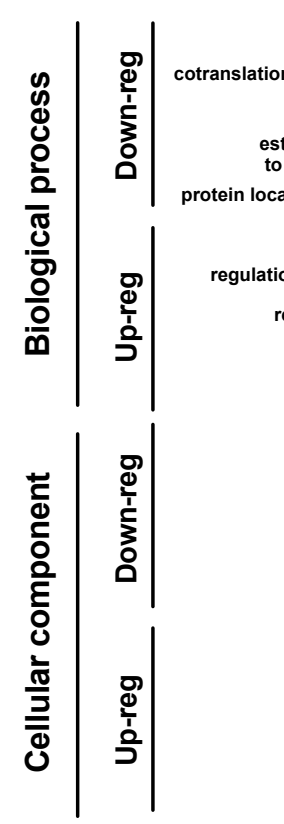

SRP-dependent cotranslational protein targeting to membrane protein targeting to ER
establishment of protein localization to endoplasmic reticulum to

synapse organization

regulation of synapse organization synaptic signaling

behavior

ribosome

ribosomal subunit

cytosolic ribosome

large ribosomal subunit

cytosolic large ribosomal subunit

glutamatergic synapse

postsynapse

synapse

postsynaptic specialization

synaptic membrane

structural constituent of ribosome

structural molecule activity

ํㅗㅀ

oxidoreductase activity, acting on NAD(P)H,

quinone or similar compound as acceptor

NADH dehydrogenase activity

NADH dehydrogenase (ubiquinone) activity

voltage-gated cation channel activity

GTPase activity

protein binding

binding

voltage-gated ion channel activity

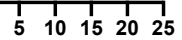

p value: $-\log _{10}$

Ribosome DEGs

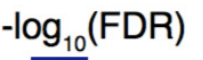

$\mathbf{F}$

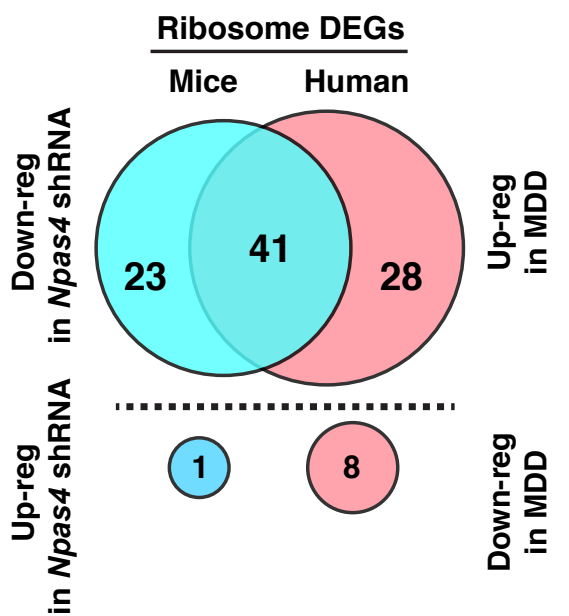


A

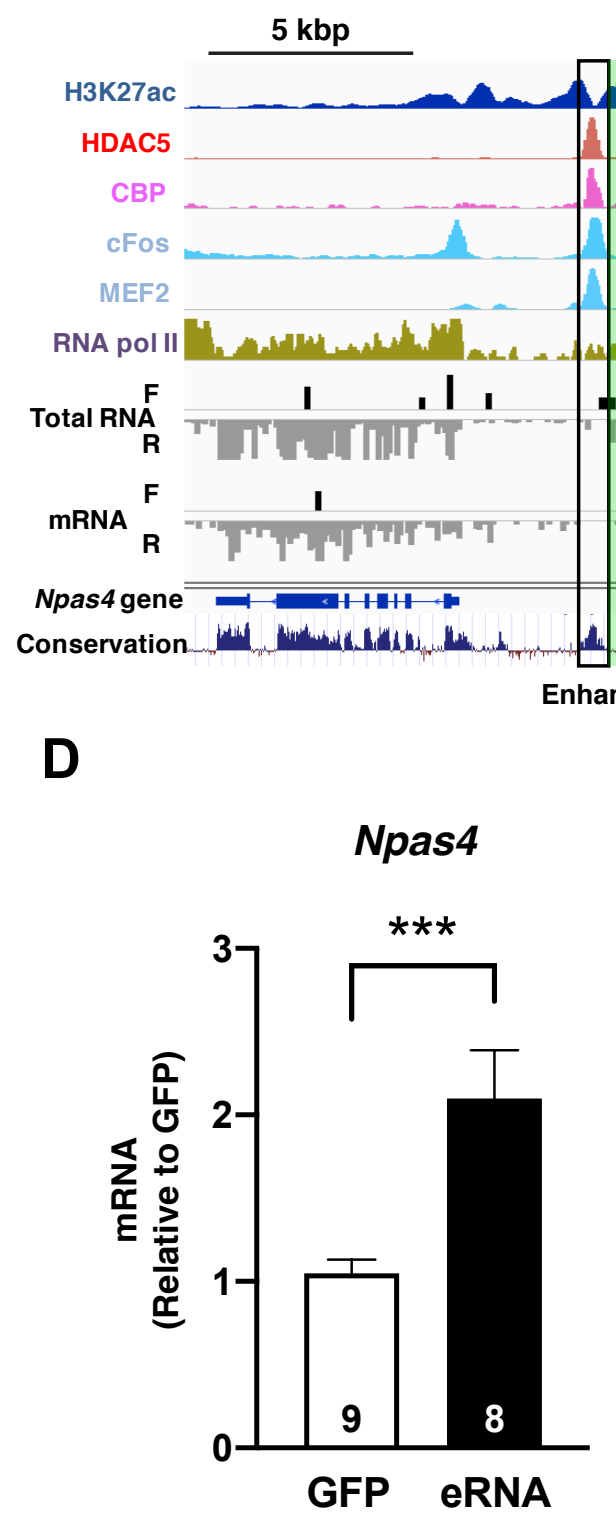

G

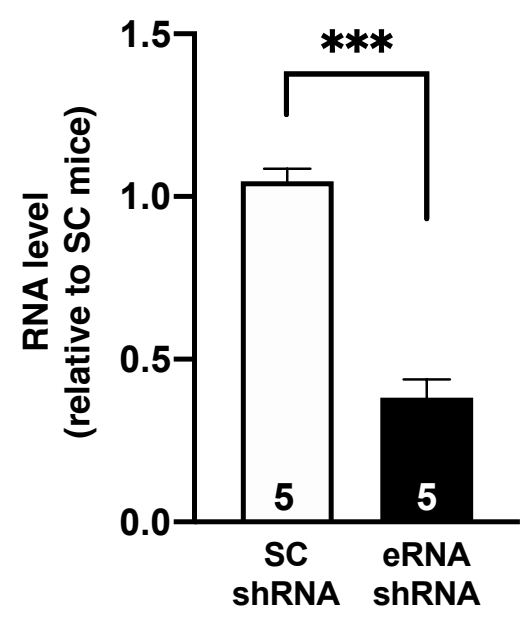

eRNA

B

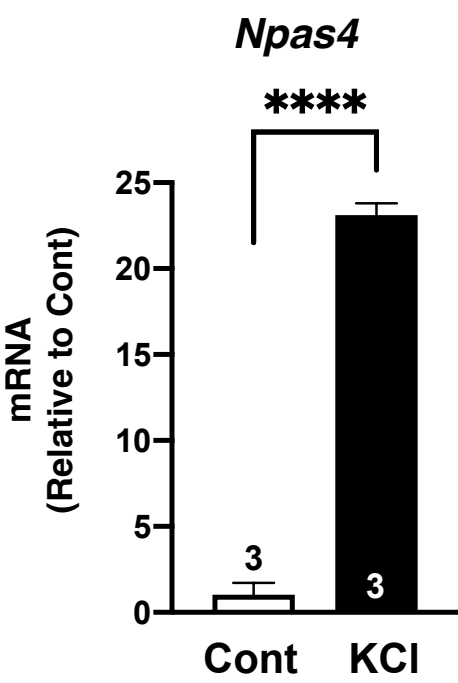

C

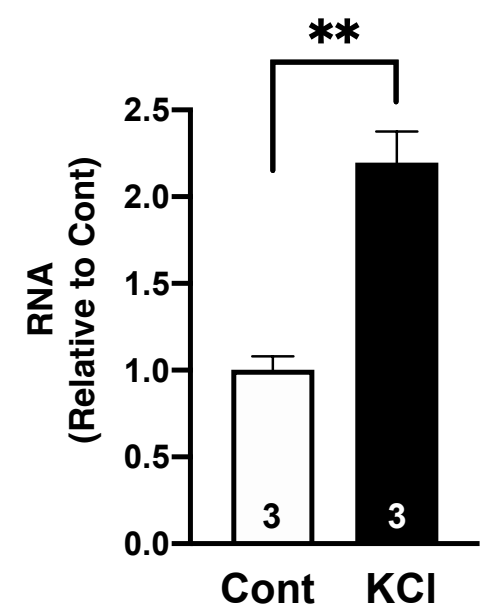

eRNA
$\mathbf{F}$
$\mathbf{E}$

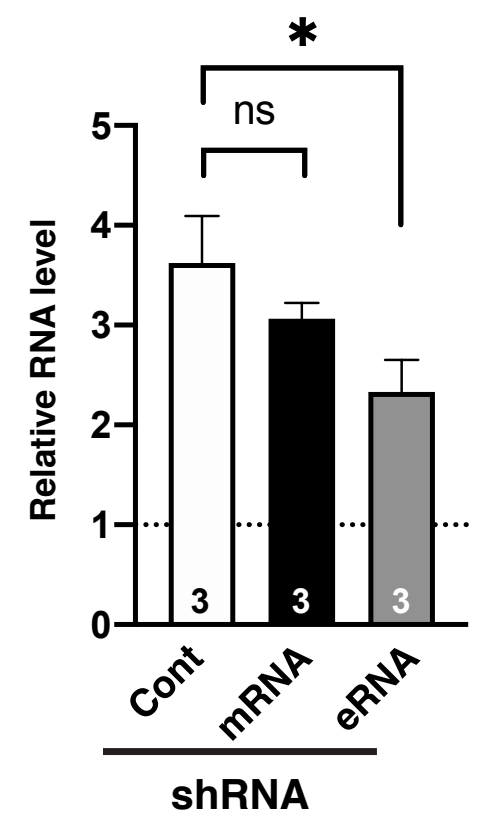

H

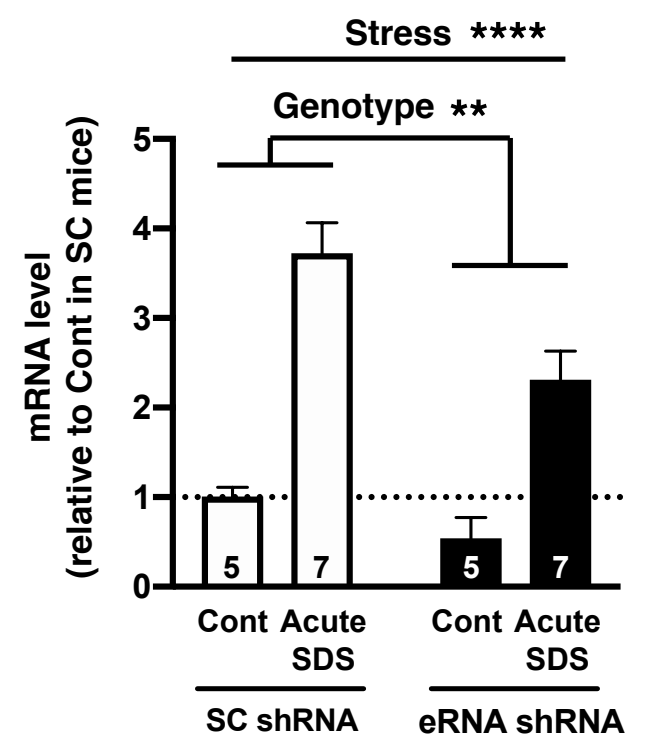

Npas4

I
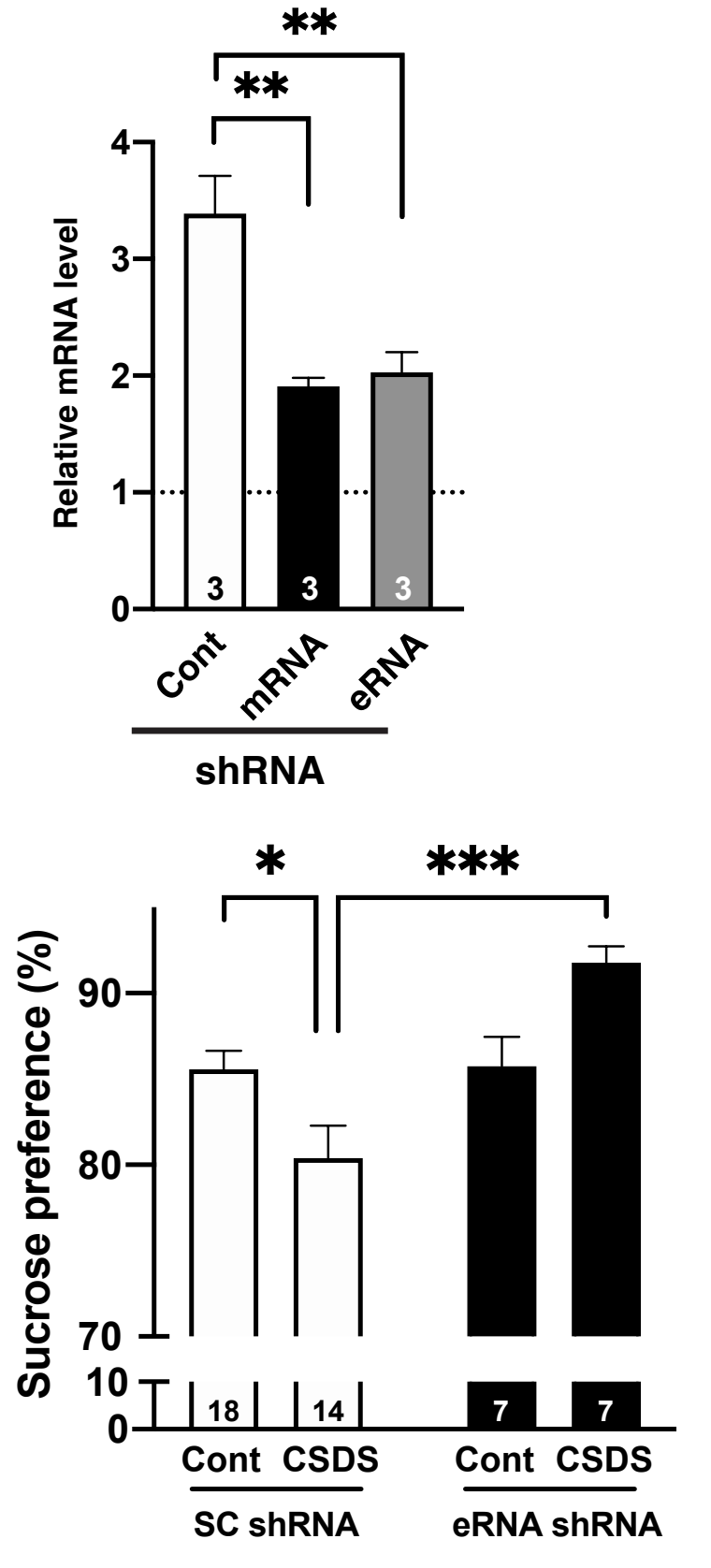